\title{
20 jaar semencryopreservatie: haalbaarheid en verwijspatronen
}

\author{
Stefanus P. T. Vinken ${ }^{1}$. Willem P. A. Boellaard ${ }^{2} \cdot$ Gert Dohle $^{2} \cdot$ Marij Dinkelman-Smit $^{2}$
}

Published online: 6 March 2018

(c) The Author(s) 2018

\section{Samenvatting}

Behandeling van kanker kan de spermatogenese aantasten, met infertiliteit tot gevolg. Semencryopreservatie voorafgaand aan gonadotoxische behandeling kan de vruchtbaarheid van mannelijke kankerpatiënten veiligstellen. Gedurende 20 jaar zijn 1.018 patiënten tussen 12 en 50 jaar oud, met Hodgkin-lymfoom $(n=194)$, non-Hodgkin lymfoom $(n=110)$, leukemie $(n=126)$ of testiculaire kiemceltumoren $(n=588)$ verwezen naar één centrum voor semencryopreservatie. De incidentie van deze kankertypen in het adherentiegebied en de incidentie van regionale semencryopreservatie werd gebruikt om een verwijsratio te berekenen. Semencryopreservatie was succesvol bij 856 van de 1.018 patiënten $(84,1 \%)$. De mediane jaarlijkse verwijsratio bij hematologische maligniteiten en testiculaire stamceltumoren was respectievelijk $17 \%$ en $31 \%$. De regionale verwijzing bij hematologische maligniteiten daalde na 2005 fors, tot een minimum van $2 \%$ in 2009 , terwijl deze toenam bij testiculaire kiemceltumoren. Onze resultaten tonen aan dat verwijzing voor semencryopreservatie bij patiënten met een hematologische maligniteit in de fertiele leeftijd suboptimaal is.

Trefwoorden semencryopreservatie $\cdot$ verwijzing $\cdot$ fertiliteit $\cdot$ hematologische maligniteiten $\cdot$ testiculaire kiemceltumoren

\section{0 years of semen cryopreservation: feasibility and referral behavior}

\begin{abstract}
Treatment of cancer can affect spermatogenesis resulting in infertility. Semen cryopreservation prior to gonadotoxic treatment can be offered to secure future fertility in male cancer patients. During 20 years 1,018 patients referred for semen cryopreservation in fertile age with Hodgkin disease $(n=194)$, non-Hodgkin lymphoma $(n=110)$, leukemia $(n=126)$ and testicular germ cell tumor $(n=588)$ were followed up. Incidence of these cancers and incidence of regional semen cryopreservation was used to calculate a referral rate. Semen cryopreservation was successful in 856 of 1,018 patients $(84.1 \%)$. Median yearly referral rate was respectively $17 \%$ and $31 \%$ in hematological malignancies and testicular germ cell tumor. Regional referral rate in hematological malignancies dropped dramatically after 2005 to a minimum of $2 \%$ in 2009. The incidence of TGCT and referral rate for fertility preservation in these patients increased over time. Our result show that referral of for semen cryopreservation in patients with hematological malignancies in fertile age is suboptimal.
\end{abstract}

Keywords semen cryopreservation $\cdot$ fertility $\cdot$ referral $\cdot$ hematological malignancies $\cdot$ testicular germ cell tumors

\section{Introductie}

$\triangle$ dr. Marij Dinkelman-Smit m.smit.3@erasmusmc.nl

1 Amphia Ziekenhuis, Breda, Nederland

2 Erasmus MC, Rotterdam, Nederland
De overleving van patiënten met een maligniteit is de afgelopen decennia sterk verbeterd, met name door combinatiechemotherapie-schema's. De verbeterde overleving gaat gepaard met toenemende aandacht voor langetermijneffecten van oncologische behandelingen, waaronder gonadotoxische schade, die kan leiden tot (ir)reversibele infertiliteit. Oncologische patiënten rapporteren verlies van kwaliteit van leven wanneer zij ten gevolge van de therapie geen kinderen kunnen verwekken [1, 2]. Daarnaast kan subferti- 
liteit het zelfvertrouwen, de identiteit, de seksualiteit en het zelfbeeld nadelig beïnvloeden [3].

Nationale en internationale richtlijnen adviseren om fertiliteitspreservatie te bespreken met mannen in de vruchtbare leeftijd bij wie kanker wordt gediagnosticeerd. Na semencryopreservatie kan, in geval van postchemotherapieazoöspermie, het eigen gecryopreserveerde semen gebruikt worden voor geassisteerde voortplanting. In $30-50 \%$ van de gevallen leidt deze behandeling tot geboorte van een kind $[4,5]$.

Semencryopreservatie moet voorafgaand aan de gonadotoxische behandeling verricht worden [2]. Uit een systematische review van internationale studies met oncologische patiënten bleek dat, ten tijde van de kankerdiagnose, in wisselende mate (30-87\% van de gevallen) counseling plaatsvindt over fertiliteit, effecten van de therapie op fertiliteit en fertiliteitspreservatie [6]. In de dagelijkse praktijk is het bespreken van fertiliteit niet de eerste prioriteit tijdens een slechtnieuwsgesprek over een kankerdiagnose. Behandelend artsen rapporteren dat zij dit onderwerp achterwege laten, omdat zij onvoldoende kennis hebben van fertiliteitspreservatie, moeite hebben met het inschatten van het risico op therapie-geïnduceerde infertiliteit, vanwege de emotionele belasting die zo'n gesprek met zich meebrengt, omdat zij een informatieoverload bij de patiënt willen voorkomen, omdat zij het spreken over een slechte prognose nijpender achten dan behoud van fertiliteit, en omdat zij uitstel van behandeling willen voorkomen [7-11]. Een deel van deze argumenten kan ondervangen worden door de counseling over te laten aan de fertiliteitspecialist [12]. In Nederland is dat een uroloog met andrologische expertise, een gynaecoloog met voortplantingsgeneeskunde als aandachtsgebied, een fertiliteitsarts die is gespecialiseerd in geassisteerde voortplanting of een embryoloog.

Semen voor cryopreservatie wordt bij voorkeur verkregen door middel van masturbatie, maar wanneer geen ejaculaat verkregen kan worden, of bij azoöspermie, kunnen met elektro-ejaculatie of chirurgisch zaadcellen verkregen worden (oncoTESE: TEsticulaire Sperma Extractie) [13]. De polikliniek Andrologie van het Erasmus MC is sinds 1980 een regionaal verwijscentrum voor mannelijke infertiliteitscounseling, infertiliteitsbehandeling en fertiliteitspreservatie.

Van Casteren et al. deden reeds onderzoek naar de oorzaken van verminderde semenkwaliteit ten tijde van semencryopreservatie en geassisteerde voortplanting met gecryopreserveerd semen $[5,14]$. In deze studie is specifiek de semenkwaliteit onderzocht van patiënten met de ziekte van Hodgkin (HD), non-Hodgkin-lymfoom (NHL), leukemie en testiculaire kiemceltumoren (TGCT). Daarnaast onderzochten wij verwijspatronen voor semencryopreservatie van kankerpatiënten in onze regio.

\section{Materiaal en methode}

De resultaten van semencryopreservatie in het Erasmus MC worden sinds 1983 geregistreerd in een database. Voor deze analyse in ons onderzoek werd een selectie gemaakt van patiënten met de diagnose HD, NHL, leukemie of TGCT tussen 12 en 50 jaar oud, die tussen 1995 en 2014 verwezen werden voor semencryopreservatie. HD, NHL, leukemie en TGCT zijn de meest voorkomende maligniteiten bij mannen in de vruchtbare leeftijd waarvan de behandeling een bedreiging vormt voor de fertiliteit. Andere maligniteiten zijn in deze analyse niet meegenomen, omdat die weinig voorkwamen. Verwijzers waren hematologen, oncologen, urologen en kinderoncologen uit het Erasmus MC of regionale ziekenhuizen.

\section{Semencryopreservatie}

Patiënten produceerden een ejaculaat door middel van masturbatie. Semenkwaliteit werd bepaald op basis van de op dat moment geldende editie van de World Health Organization guideline Laboratory Manual for the Examination and Processing of Human Semen. Wanneer er geen of alleen immotiele zaadcellen werden gevonden, was semencryopreservatie niet mogelijk. Het spreekt voor zich dat cryopreservatie niet mogelijk was bij azoöspermie, maar ook bij cryptozoöspermie kunnen motiele zaadcellen ontbreken. Onze definitie van aspermie luidt 'het onvermogen tot het inleveren van een ejaculaat onder invloed van algeheel ziekzijn of stress, of ten gevolge van retrograde ejaculatie of anejaculatie'. Tot slot werd de concentratie zaadcellen bij zeer lage hoeveelheden niet altijd gedocumenteerd. Deze uitslag werd voor de studie gerapporteerd als 'missing'. Er werd gestreefd naar cryopreservatie van 20 rietjes. Binnen de beschikbare tijd voor aanvang van therapie werden zo nodig en zo mogelijk meerdere ejaculaten gecryopreserveerd. Voor deze studie werden de resultaten van het eerst geproduceerde sample gebruikt.

De resultaten van de semenanalyse, het geanticipeerde effect van de voorgestelde gonadotoxische therapie, de verwachtingen over fertiliteit na de oncologische behandeling en geassisteerde voortplanting met gecryopreserveerd semen, werden besproken met de patiënt door een uroloogandroloog of een getrainde arts-assistent. Sinds 2015 wordt oncoTESE structureel aangeboden aan patiënten bij wie een azoöspermie werd geconstateerd.

\section{Patiënt- en therapiekarakteristieken}

Stadium van de ziekte, therapievoorstel en mortaliteit werden aangevuld met beschikbare gegevens uit het elektronisch patiëntendossier. De variatie in classificatie en ziektestadium bij de leukemiepatiënten was te groot voor stra- 
Tabel 1 Aantal patiënten met succesvolle semencryopreservatie, weergegeven als zaadcelconcentratie op basis van de WHO-criteria voor semenanalyse, gestratificeerd naar diagnose

\begin{tabular}{|c|c|c|c|c|c|}
\hline & $\begin{array}{l}\text { HD } \\
n=194 \\
(19,1 \%)\end{array}$ & $\begin{array}{l}\text { NHL } \\
n=110 \\
(10,8 \%)\end{array}$ & $\begin{array}{l}\text { leukemie } \\
n=126 \\
(12,4 \%)\end{array}$ & $\begin{array}{l}\text { TGCT } \\
n=588 \\
(57,8 \%)\end{array}$ & $\begin{array}{l}\text { totaal cohort } \\
n=1.018\end{array}$ \\
\hline \multicolumn{6}{|l|}{ semencryopreservatie uitgevoerd (\%) } \\
\hline ja & $164(84,5)$ & $89(80,9)$ & $100(79,4)$ & $503(85,5)$ & $856(84,1)$ \\
\hline nee & $30(15,5)$ & $21(19,1)$ & $26(20,6)$ & $85(14,5)$ & $162(15,9)$ \\
\hline \multicolumn{6}{|l|}{ spermakwaliteit (\%) } \\
\hline normozoöspermie $\left(>15,00 \times 10^{6} / \mathrm{ml}\right)$ & $98(50,5)$ & $64(58,2)$ & $64(50,8)$ & $246(41,8)$ & $472(46,3)$ \\
\hline oligozoöspermie $\left(5,00-14,99 \times 10^{6} / \mathrm{ml}\right)$ & $26(13,4)$ & $12(10,9)$ & $15(11,9)$ & $106(18,0)$ & $159(15,6)$ \\
\hline $\begin{array}{l}\text { ernstige oligozoöspermie } \\
\quad\left(1,00-4,99 \times 10^{6} / \mathrm{ml}\right)\end{array}$ & $13(6,7)$ & $5(4,5)$ & $9(7,1)$ & $87(14,8)$ & $114(11,2)$ \\
\hline cryptozoöspermie $\left(0,01-0,99 \times 10^{6} / \mathrm{ml}\right)$ & $7(3,6)$ & $3(2,7)$ & $1(0,8)$ & $47(8,0)$ & $58(5,7)$ \\
\hline azoöspermie & $8(4,1)$ & $6(5,5)$ & $10(7,9)$ & $39(6,6)$ & $63(6,2)$ \\
\hline aspermie & $6(3,1)$ & $5(4,5)$ & $4(3,2)$ & $4(0,7)$ & $19(1,9)$ \\
\hline missing & $36(18,6)$ & $15(13,6)$ & $23(18,3)$ & $59(10,0)$ & $133(13,1)$ \\
\hline
\end{tabular}

HD Hodgkin-lymfoom, NHL non-Hodgkin-lymfoom, TGCT testiculaire stamceltumor

Tabel 2 Studiecohort dat is ingedeeld naar ziekte-ernst, uitgedrukt als mortaliteit, stadium en risico op infertiliteit

\begin{tabular}{|c|c|c|c|c|c|}
\hline & $\begin{array}{l}\text { HD } \\
n=194\end{array}$ & $\begin{array}{l}\text { NHL } \\
n=110\end{array}$ & $\begin{array}{l}\text { leukemie } \\
n=126\end{array}$ & $\begin{array}{l}\text { TGCT } \\
n=588\end{array}$ & $\begin{array}{l}\text { totaal cohort } \\
n=1.018\end{array}$ \\
\hline$\overline{\text { mortaliteit (\%) }}$ & $19(9,8)$ & $28(25,5)$ & $34(27,0)$ & $13(2,2)$ & $95(9,3)$ \\
\hline \multicolumn{6}{|l|}{ stadium (\%) } \\
\hline I & $29(14,9)$ & $26(23,6)$ & & $178(30,3)$ & \\
\hline II & $82(42,3)$ & $22(20,0)$ & & $186(31,6)$ & \\
\hline III & $33(17,0)$ & $11(10,0)$ & & $15(2,6)$ & \\
\hline IV & $30(15,5)$ & $25(22,7)$ & & $58(9,9)$ & \\
\hline missing & $20(10,3)$ & $26(23,6)$ & & $151(25,7)$ & \\
\hline \multicolumn{6}{|l|}{ therapierisico } \\
\hline hoog risico & 13 & 22 & 32 & 10 & 76 \\
\hline gemiddeld risico & 27 & 0 & 8 & 165 & 200 \\
\hline laag risico & 0 & 3 & 5 & 0 & 8 \\
\hline onduidelijk & 0 & 0 & 1 & 2 & 3 \\
\hline missing & 154 & 85 & 80 & 411 & 730 \\
\hline
\end{tabular}

$H D$ Hodgkin-lymfoom, $N H L$ non-Hodgkin-lymfoom, $T G C T$ testiculaire stamceltumor

tificatie. Voor iedere patiënt werd daarom het risico op inductie van infertiliteit ingeschat op basis van de chemotherapie-indeling zoals beschreven door Wallace et al. [15] Therapieschema's werden ingedeeld als respectievelijk laag, gemiddeld en hoog risico op gonadotoxische schade (de indeling van de gonadotoxiciteit per therapieschema is te vinden op www.oncoline.nl). Stamceltransplantatie werd geclassificeerd als een hoog risico, omdat bij stamceltransplantatie conditionering plaatsvindt met hoogrisico-chemotherapie, al dan niet in combinatie met totale lichaamsbestraling. Als een kuurschema niet beschreven was door Wallace et al., werd PubMed geraadpleegd. Als literatuur over gonadale functie na blootstelling aan chemotherapeutica ontbrak, werd het potentiële risico ingedeeld als onbekend.

\section{Verwijsratio}

Het jaarlijks aantal verwijzingen voor semencryopreservatie werd per diagnosegroep berekend en gestratificeerd naar leeftijdsintervallen van 10 jaar. Op basis van historische verwijspatronen werd vastgesteld wat het adherentiegebied van het Erasmus MC is voor semencryopreservatie.

De gepoolde incidentiecijfers van HD, NHL, leukemie en TGCT bij mannen tussen 12 en 50 jaar in dit adherentiegebied werden opgevraagd bij het IKNL. De verwijsratio werd vervolgens berekend door het absolute aantal verwezen patiënten per jaar te delen door de gepoolde incidentie in het adherentiegebied. Verwijsratio's werden berekend over intervallen van vijf jaar en gestratificeerd naar leeftijdscategorieën teneinde de trends in de tijd en het effect van leeftijd van de patiënt te analyseren. 


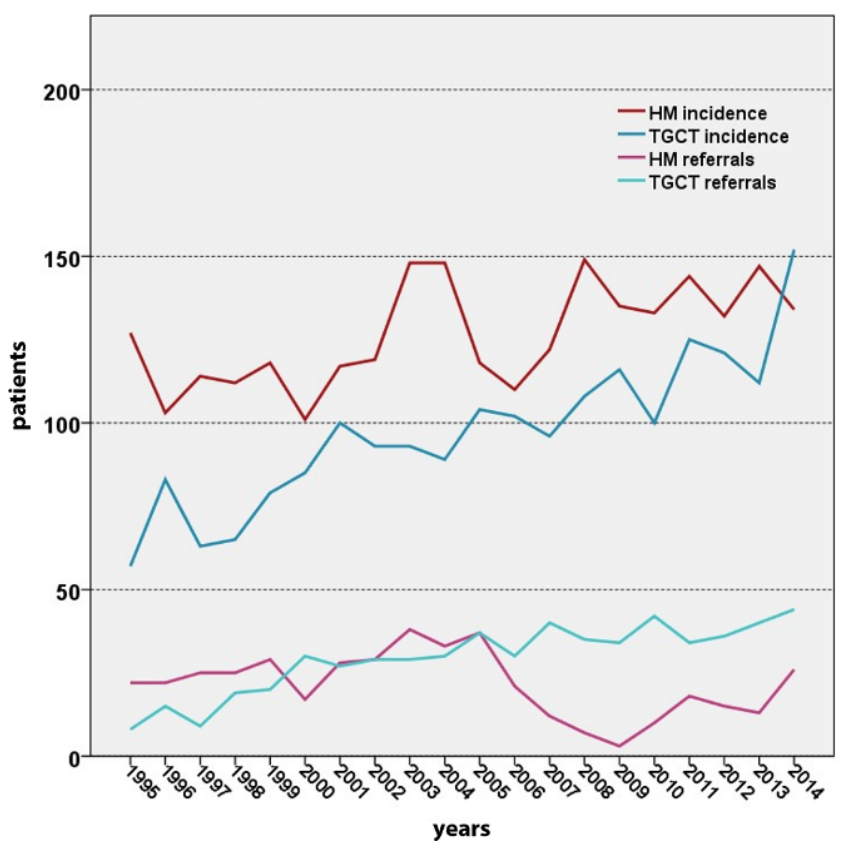

Figuur 1 De ratio tussen de incidentie van patiënten met hematologische maligniteiten (HM) en testiculaire stamceltumoren (TGCT) en de verwijzing voor cryopreservatie in de regio Zuidwest Nederland

\section{Data-analyse}

Statistische analyse werd uitgevoerd met IBM SPSS Statistics 20.0. Een $p$-waarde $<0,05$ werd beschouwd als statistisch significant. De Kruskal-Wallis 1-way ANOVA non-parametrische test werd gebruikt om de niet normaal verdeelde variabele 'semenconcentratie' te vergelijken met categorische variabelen. De verwijsratio's waren niet normaal verdeeld; resultaten werden weergeven als mediaan met kwartielen van $25 \%$ en $75 \%$.

\section{Resultaten}

Tussen 1995 en 2014 werden 1.018 mannelijke patiënten tussen 12 en 48 jaar (mediaan 27 jaar) met HD $(n=194)$, NHL $(n=110)$, leukemie $(n=126)$ of TGCT $(n=588)$ verwezen voor semencryopreservatie. Semencryopreservatie was succesvol bij 856 patiënten $(84,1 \%)$. De hoogste invriesratio werd gevonden bij mannen met TGCT $(85,5 \%)$ en de laagste bij mannen met leukemie $(79,4 \%)$. Zie tab. 1 .

De mediane semenconcentratie was 17 miljoen/ml (range 0-387 miljoen $/ \mathrm{ml}$ ). De spermakwaliteit uitgedrukt als zaadcelconcentratie was significant lager bij TGCTpatiënten vergeleken met patiënten in de overige diagnosegroepen $(p<0,001)$. Er werd geen significant verschil in semenconcentratie gevonden bij patiënten met HD, NHL of leukemie.

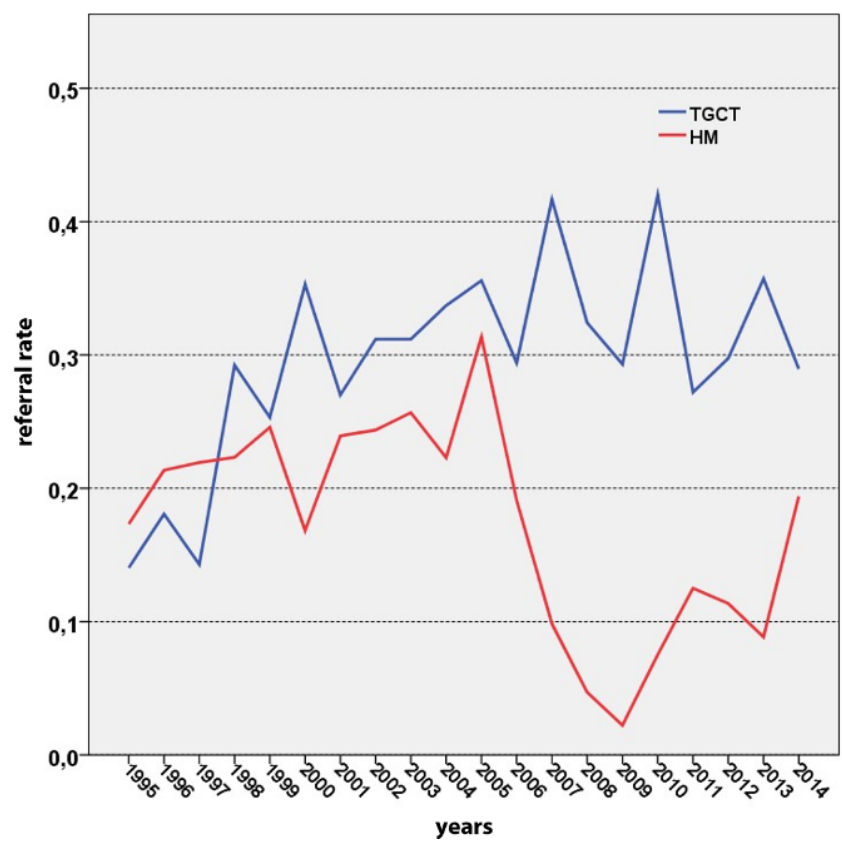

Figuur 2 De verwijsratio tussen de incidentie van patiënten met hematologische maligniteiten (HM) en testiculaire kiemceltumoren (TGCT) en de patiënten die werden verwezen voor cryopreservatie vanwege HM en TGCT per jaar

Niet-succesvolle semencryopreservatie werd het vaakst veroorzaakt door onvoldoende semenkwaliteit bij TGCTpatiënten. Bij 14,6\% van de patiënten met een testistumor werd azoöspermie of cryptozoöspermie gevonden, versus $7,7 \%$ bij HD, 8,2\% bij NHL en 8,7\% bij leukemie. Aspermie kwam voor bij $19(1,9 \%)$ patiënten in het gehele cohort. Het onvermogen om een ejaculaat in te leveren, werd vaker gezien bij mannen met een hematologische maligniteit in vergelijking tot mannen met een testistumor $(3,5 \%$ versus $0,7 \%)$.

\section{Patiëntkarakteristieken}

Tijdens de dataverzameling in 2016 waren 95 patiënten overleden $(9,3 \%)$. De mediane follow-up was 11,3 jaar (range 1,6-21,6). De hoogste mortaliteit werd gevonden onder NHL-patiënten $(25,5 \%)$ en leukemiepatiënten $(27,0 \%)$. Tab. 2 toont de ziektestadia. Patiënten met TGCT presenteerden zich vaak met stadium-I- $(30,3 \%)$ en stadium-IItumoren $(31,6 \%)$ en $22,7 \%$ van de mannen met NHL die verwezen werden voor semencryopreservatie presenteerden zich met stadium-IV-tumoren. Ziektestadium was niet significant geassocieerd met semenconcentratie bij patiënten met HD $(p=0,168)$, NHL $(p=0,349)$ en TGCT $(p=0,319)$.

Het therapieschema was bekend bij 288 patiënten. Therapieschema's met een hoog risico op gonadotoxiciteit kwamen vaker voor bij patiënten met NHL $(88 \%)$ en leukemie (70\%). Patiënten met HD en TGCT werden vaker bloot- 
Tabel 3 De verwijsratio per vijf jaar voor semencryopreservatie in hematologische maligniteiten en testiculaire kiemceltumoren, gestratificeerd naar leeftijdsgroep

\begin{tabular}{lllll}
\hline & $1995-1999$ & $2000-2004$ & $2005-2009$ & $2010-2014$ \\
\hline $\begin{array}{l}\text { hematologische maligniteit } \\
\text { 12-19 jaar }\end{array}$ & 0,41 & 0,46 & 0,37 & 0,41 \\
20-29 jaar & 0,50 & 0,68 & 0,30 & 0,27 \\
30-39 jaar & 0,26 & 0,25 & 0,17 & 0,14 \\
40-50 jaar & 0,03 & 0,02 & 0,02 & 0,02 \\
testiculaire kiemceltumor & & & & \\
12-19 jaar & 0,41 & 0,46 & 0,63 & 0,70 \\
20-29 jaar & 0,38 & 0,51 & 0,57 & 0,48 \\
30-39 jaar & 0,14 & 0,27 & 0,25 & 0,29 \\
40-50 jaar & 0,00 & 0,01 & 0,08 & 0,07 \\
\hline
\end{tabular}

\section{Discussie}

gesteld aan therapieschema's met een gemiddeld risico op gonadotoxiciteit (resp. $68 \%$ en $93 \%$ ).

\section{Verwijsratio}

Fig. 1 toont de jaarlijkse gepoolde incidentiecijfers van hematologische maligniteiten (HD, NHL en leukemie) en TGCT van historische verwijzers in de regio Zuidwest Nederland. In dezelfde figuur worden de jaarlijkse absolute aantallen patiënten afgebeeld die in onze regio werden verwezen voor semencryopreservatie. Fig. 2 toont de trend in verwijsratio tussen 1995 en 2014. De mediane verwijsratio voor patiënten met een hematologische maligniteit was 0,17 $(0,10-0,24)$ en voor patiënten met TGCT $0,30(0,27-0,35)$.

Gedurende de 20 jaar die deze analyse besloeg, steeg zowel de incidentie van TGCT als de verwijsratio voor semencryopreservatie bij TGCT-patiënten. Verwijzing van patiënten met een hematologische aandoening nam tussen 2005 en 2009 af van 0,31-0,02.

Verwijsratio's voor semencryopreservatie werden ook per vijf jaar gestratificeerd naar leeftijd voor hematologische maligniteiten en voor testistumoren (tab. 3). In de leeftijdscategorie 40-50 jaar was het aantal verwijzingen in beide groepen laag. Mannen tussen de 20 en 29 jaar die zich presenteerden met een testistumor in onze regio, ondernamen in ongeveer $50 \%$ van de gevallen een poging tot semencryopreservatie. In de jaren 1995-1999 en 2000-2004 waren de verwijsratio's voor leeftijdgenoten met een hematologische maligniteit hetzelfde. Sinds 2005 nam het percentage verwijzingen in deze patiëntencategorieën dramatisch af. Er is weinig variatie in het aantal verwijzingen voor semencryopreservatie bij patiënten met een hematologische maligniteit in de leeftijdscategorie 12-19 jaar (range 0,37-0,46).
In deze studie is de semenkwaliteit ten tijde van een poging tot semencryopreservatie onderzocht in een cohort van 1.018 mannelijke patiënten in de vruchtbare leeftijd met veelvoorkomende maligniteiten. Semencryopreservatie is succesvol bij 84,1\% van de patiënten met HD, NHL, leukemie of TGCT. Dit succespercentage ligt lager dan eerder beschreven succespercentages van circa $93 \%$ [16].

De analyse van niet-succesvolle semencryopreservaties geeft inzicht in de risico's op het niet kunnen invriezen van een ejaculaat. Bij patiënten met een testistumor is azoöspermie of cryptozoöspermie zonder motiele zaadcellen de belangrijkste risicofactor. De gedeelde pathofysiologie van afwijkende spermatogenese, infertiliteit, cryptorchisme en testistumorontwikkeling, zoals beschreven in het testiculaire dysgenesiesyndroom is hiervoor een mogelijke verklaring [17, 18].

De gepoolde incidentiecijfers van historische verwijzers naar ons centrum voor semencryopreservatie tonen aan dat de incidentie van TGCT de afgelopen 20 jaar is toegenomen. Dit is in lijn met de toegenomen incidentie van TGCT in West-Europa [19]. Het toegenomen verwijspatroon voor semencryopreservatie bij mannen met de diagnose testistumor in onze regio volgt deze trend. De leeftijdsdistributie illustreert de behoefte aan het veiligstellen van de vruchtbaarheid voor de toekomst, en het belang daarvan. Bij mannen in de leeftijd van 12-19 jaar oud met een testistumor is het verwijspercentage voor semencryopreservatie $70 \%$, wat tot $50 \%$ daalt bij patiënten in de leeftijd van 20-29 jaar en tot 30\% bij mannen van 30-39 jaar met een testistumor, die vaker al een compleet gezin hebben bij presentatie met een TGCT.

Patiënten met een hematologische maligniteit zijn vaker niet in staat een ejaculaat te produceren dan mannen met een testistumor $(3,5 \%$ versus $0,7 \%)$. De hoge ziektestadia ten tijde van verwijzing voor semencryopreservatie en hoge mortaliteitscijfers in ons studiecohort laten zien dat de patiënten met een hematologische maligniteit die worden verwezen ernstiger ziek zijn dan de andere patiënten die 
worden verwezen. Mogelijk is dit een verklaring voor het feit dat aspermie in deze groep vaker voorkomt. Daarnaast krijgen patiënten die zijn verwezen met hematologische maligniteiten vaker een behandeling met chemotherapie met een hoog risico op infertiliteit. Dit staat in schril contrast met de daling in het aantal verwijzingen voor semencryopreservatie voor deze patiënten in de afgelopen jaren. Het valt op dat verwijzing voor fertiliteitspreservatie door kinderoncologen deze trend niet volgt. Zorgelijk is met name de daling in het aantal verwijzingen voor semencryopreservatie van patiënten met leukemie, HD of NHL in de leeftijd van 20-39 jaar.

Aangezien de therapie voor deze aandoeningen de afgelopen decennia niet wezenlijk minder gonadotoxisch is geworden, blijft het speculeren over de oorzaak van deze onwenselijke trend. Mogelijk wordt de daling verklaard door de verschuiving van de behandeling van academische ziekenhuizen naar algemene ziekenhuizen. Het zou kunnen dat perifere behandelaars minder bekend zijn met semencryopreservatie of meer zijn gaan verwijzen naar andere klinieken die cryopreservatie aanbieden. Navraag bij klinieken op de grens van ons historisch adherentiegebied leert dat daar geen toename van aanbod is geobjectiveerd. Slechts in $10 \%$ van de gevallen wordt het semen na cryopreservatie ook daadwerkelijk gebruikt [5, 20, 21]. Mogelijk hebben publicaties daarover de belangstelling van verwijzers voor semencryopreservatie doen afnemen. De negatieve trend in de verwijsratio zette echter al in in 2005, ruim voor deze publicaties het licht zagen.

Mogelijk ervaren artsen tijdsdruk, omdat zij met de therapie willen starten, en speelt de gedachte aan mogelijk herstel van de spermatogenese na de therapie een rol. De realiteit is echter dat de spermatogenese niet herstelt bij een derde van de patiënten met NHL die zijn behandeld met CHOP (een combinatie van cyclofosfamide, doxorubicin, vincristine en prednisolon) [22]. Bij mannen met HD die behandeld worden met AVBD (doxorubicin, bleomycine, vinblastine en dacarbazine) herstelt de fertiliteit meestal wel, maar na behandeling met MOPP (mitoxine, oncovin, procarbazine en prednison) is de fertiliteit wel sterk verminderd [23].

Onze resultaten laten zien dat bij 13,8\% van de mannen in ons cohort een azoöspermie, cryptozoöspermie of een aspermie is gevonden. Bij deze patiënten kan voor de start van gonadotoxische therapie of voor radicale orchidectomie, OncoTESE worden aangeboden om fertiliteitspreservatie toch mogelijk te maken. Wij toonden eerder aan dat slechts $20 \%$ van de patiënten met een testistumor in onze regio semencryopreservatie krijgt aangeboden vóór de radicale orchidectomie [24]. Het is van groot belang om de patiënt voor de start van gonadotoxische therapie of voor de radicale orchidectomie over fertiliteitspreservatie te informeren, al dan niet door een fertiliteitsspecialist.
Beperkingen van deze studie zijn de retrospectieve opzet ervan en het feit dat de verwijsratio is berekend op basis van historische verwijspatronen. Deze beperkingen kunnen invloed hebben op de resultaten. De trend in de afname van het aantal verwijzing voor semencryopreservatie bij mannen met een hematologische maligniteit, is desalniettemin verontrustend.

\section{Conclusie}

Wij concluderen dat zowel de timing van de semencryopreservatie als heldere verwijsstructuren en aanbod in de regio essentieel zijn om de zorg en nazorg voor kankerpatiënten te optimaliseren.

Open Access This article is distributed under the terms of the Creative Commons Attribution 4.0 International License (http:// creativecommons.org/licenses/by/4.0/), which permits unrestricted use, distribution, and reproduction in any medium, provided you give appropriate credit to the original author(s) and the source, provide a link to the Creative Commons license, and indicate if changes were made.

\section{Literatuur}

1. Schover LR, Brey K, Lichtin A, Lipschultz LI, Jeha S. Knowledge and experience regarding cancer, infertility, and sperm banking in younger male survivors. J Clin Oncol. 2002;20(7):1880-9.

2. Lee SJ, Schover LR, Partridge AH, et al. American Society of Clinical Oncology recommendations on fertility preservation in cancer patients. J Clin Oncol. 2006;24(18):2917-31.

3. Tschudin S, Bitzer J. Psychological aspects of fertility preservation in men and women affected by cancer and other life-threatening diseases. Hum Reprod Update. 2009;15(5):587-97.

4. Bizet P, Saias-Magnan J, Jouve E, et al. Sperm cryopreservation before cancer treatment: a 15-year monocentric experience. Reprod Biomed Online. 2012;24(3):321-30.

5. Casteren NJ van, Santbrink EJ van, Inzen W van, Romijn JC, Dohle GR. Use rate and assisted reproduction technologies outcome of cryopreserved semen from 629 cancer patients. Fertil Steril. 2008;90(6):2245-50.

6. Taylor JF, Ott MA. Fertility preservation after a cancer diagnosis: a systematic review of adolescents', parents', and providers' perspectives, experiences, and preferences. J Pediatr Adolesc Gynecol. 2016;29(6):585-98.

7. Arafa MA, Rabah DM. Attitudes and practices of oncologists toward fertility preservation. J Pediatr Hematol Oncol. 2011;33(3): 203-7.

8. Clayman ML, Harper MM, Quinn GP, Reinecke J, Shah S. Oncofertility resources at NCI-designated comprehensive cancer centers. J Natl Compr Canc Netw. 2013;11(12):1504-9.

9. Eiser C, Arden-Close E, Morris K, Pacey AA. The legacy of sperm banking: how fertility monitoring and disposal of sperm are linked with views of cancer treatment. Hum Reprod. 2011;26(10):2791-8.

10. Fay L, Collins I, Kennedy J. Awareness of strategies for fertility preservation among Irish cancer specialists. Hum Fertil. 2011;14(2):64.

11. Gilbert E, Adams A, Mehanna H, Harrison B, Hartshorne GM. Who should be offered sperm banking for fertility preservation? 
A survey of UK oncologists and haematologists. Ann Oncol. 2011;22(5):1209-14.

12. Martinez F, Devesa M, Coroleu B, et al. Cancer and fertility preservation: Barcelona consensus meeting. Gynecol Endocrinol. 2013;29(4):285-91.

13. Moss JL, Choi AW, Fitzgerald Keeter MK, Brannigan RE. Male adolescent fertility preservation. Fertil Steril. 2016;105(2):267-73.

14. Casteren NJ van, Boellaard WP, Romijn JC, Dohle GR. Gonadal dysfunction in male cancer patients before cytotoxic treatment. Int J Androl. 2010;33(1):73-9.

15. Wallace WHB, Anderson RA, Irvine DS. Fertility preservation for young patients with cancer: who is at risk and what can be offered? Lancet Oncol. 2005;6(4):209-18.

16. Ferrari S, Paffoni A, Filippi F, Busnelli A, Vegetti W, Somigliana E. Sperm cryopreservation and reproductive outcome in male cancer patients: a systematic review. Reprod Biomed Online. 2016;33(1):29-38.

17. Walsh TJ, Croughan MS, Schembri M, Chan JM, Turek PJ. Increased risk of testicular germ cell cancer among infertile men. Arch Intern Med. 2009;169(4):351-6.

18. Moller H, Prener A, Skakkebaek NE. Testicular cancer, cryptorchidism, inguinal hernia, testicular atrophy, and genital malformations: case-control studies in Denmark. Cancer Causes Control. 1996;7(2):264-74.

19. Bray F, Richiardi L, Ekbom A, Pukkala E, Cuninkova M, Moller $\mathrm{H}$. Trends in testicular cancer incidence and mortality in 22 Euro- pean countries: continuing increases in incidence and declines in mortality. Int J Cancer. 2006;118(12):3099-111.

20. Garcia A, Herrero MB, Holzer H, Tulandi T, Chan P. Assisted reproductive outcomes of male cancer survivors. J Cancer Surviv. 2015;9(2):208-14.

21. Botchan A, Karpol S, Lehavi O, et al. Preservation of sperm of cancer patients: extent of use and pregnancy outcome in a tertiary infertility center. Asian J Androl. 2013;15(3):382-6.

22. Howell SJ, Shalet SM. Spermatogenesis after cancer treatment: damage and recovery. J Natl Cancer Inst Monographs. 2005;34: $12-7$.

23. Tal R, Botchan A, Hauser R, Yogev L, Paz G, Yavetz H. Followup of sperm concentration and motility in patients with lymphoma. Hum Reprod. 2000;15(9):1985-8.

24. Dinkelman-Smit M, Boellaard W, Timmer E, Casteren N, Dohle G. Radicaal anders: waarom semencryopreservatie bij mannen met een testistumor moet worden aangeboden vóór de radicale orchiëctomie. Tijdschr Urol. 2016;6:97-103.

drs. Stefanus P.T. Vinken anios urologie

drs. Willem P.A. Boellaard uroloog, klinisch androloog

dr. Gert Dohle uroloog, klinisch androloog

dr. Marij Dinkelman-Smit uroloog, klinisch androloog 